\title{
Development Analysis of Chinese and American Technology Innovation Board Based on Time Series Model
}

\author{
Wei Wei ${ }^{1,}$,, Ma Yuyi², Hu Junlong ${ }^{1}$ \\ ${ }^{1}$ School of Energy and Mechanical Engineering, Shanghai University of Electric Power, Shanghai, China \\ ${ }^{2}$ School of Economics and Management, Shanghai Ocean University, Shanghai, China
}

Email address:

1452903694@qq.com (Wei Wei), Yuyim99@yahoo.com (Ma Yuyi), 2035149349@qq.com (Hu Junlong)

${ }^{*}$ Corresponding author

\section{To cite this article:}

Wei Wei, Ma Yuyi, Hu Junlong. Development Analysis of Chinese and American Technology Innovation Board Based on Time Series Model. European Business \& Management. Vol. 5, No. 5, 2019, pp. 55-60. doi: 10.11648/j.ebm.20190505.11

Received: October 11, 2019; Accepted: October 30, 2019; Published: November 6, 2019

\begin{abstract}
The technology innovation board mainly serves scientific and technological innovation enterprises that conform to the national strategy, breakthrough key core technologies and have high market recognition. It is a crucial step for China to implement the strategy of strengthening China through science and technology and can promote the mutual growth of the capital market and scientific and technological innovation. For its research on the development of our country has a far-reaching significance. First, we conducted cluster analysis, divided the company into different industries, took the price-sales ratio as the valuation level, established a time series model, and analyzed the valuation premium or discount of various industries in China and the United States. The relation between market index, underlying index, and liquidity index is obtained by polynomial regression fitting equation. When forecasting the fundamental indicators and liquidity indicators of China and our market in 2019, the author USES the existing data to predict the fundamental indicators and liquidity indicators in 2019 by using the time series model and then obtains the valuation indicators of the two markets in 2019. Finally, in order to study the development of gem, we consulted the fundamental data of 93 companies, referred to the quantitative stock index model of our market and liquidity index of the Chinese market, and thus predicted the valuation level of the first batch of tech create board companies after listing.
\end{abstract}

Keywords: Time Series Model, Cluster Analysis, Multiple Factor Regression Fitting, Grayscale Prediction, Factor Weight Analysis

\section{Introduction}

In order to enhance China's competitiveness in science and innovation, vigorously develop science and technology, and realize the dream of becoming a high power through science and technology [1], general secretary Xi Jinping announced the establishment of the science and innovation board at the opening ceremony of the first China international import expo [2]. The sci-tech innovation edition mainly serves the sci-tech innovation enterprises that conform to the national strategy, break through the key and core technologies [3], and enjoy high market recognition. It is a crucial step for China to implement the strategy of strengthening itself through science and technology and can promote the mutual growth of the capital market and sci-tech innovation [4].
The establishment of a science and technology innovation board is undoubtedly an opportunity for investors. However, because of the valuation problem of science and technology innovation board enterprises, there is a hidden crisis [5]. Gem listed enterprises are not required to have earnings performance, cannot use the $\mathrm{p} / \mathrm{e}$ method valuation; Companies listed on NASDAQ, a similar American market, can be valued by a price-to-sales ratio. However, domestic and foreign companies are quite different in many aspects, and the market environment at home and abroad is quite different [6], which will lead to the valuation premium or discount of such listed companies in Chinese and American stock markets. Therefore, how to analyze the trend of the science and technology innovation board is a crucial issue [7]. 


\section{Model Establishment}

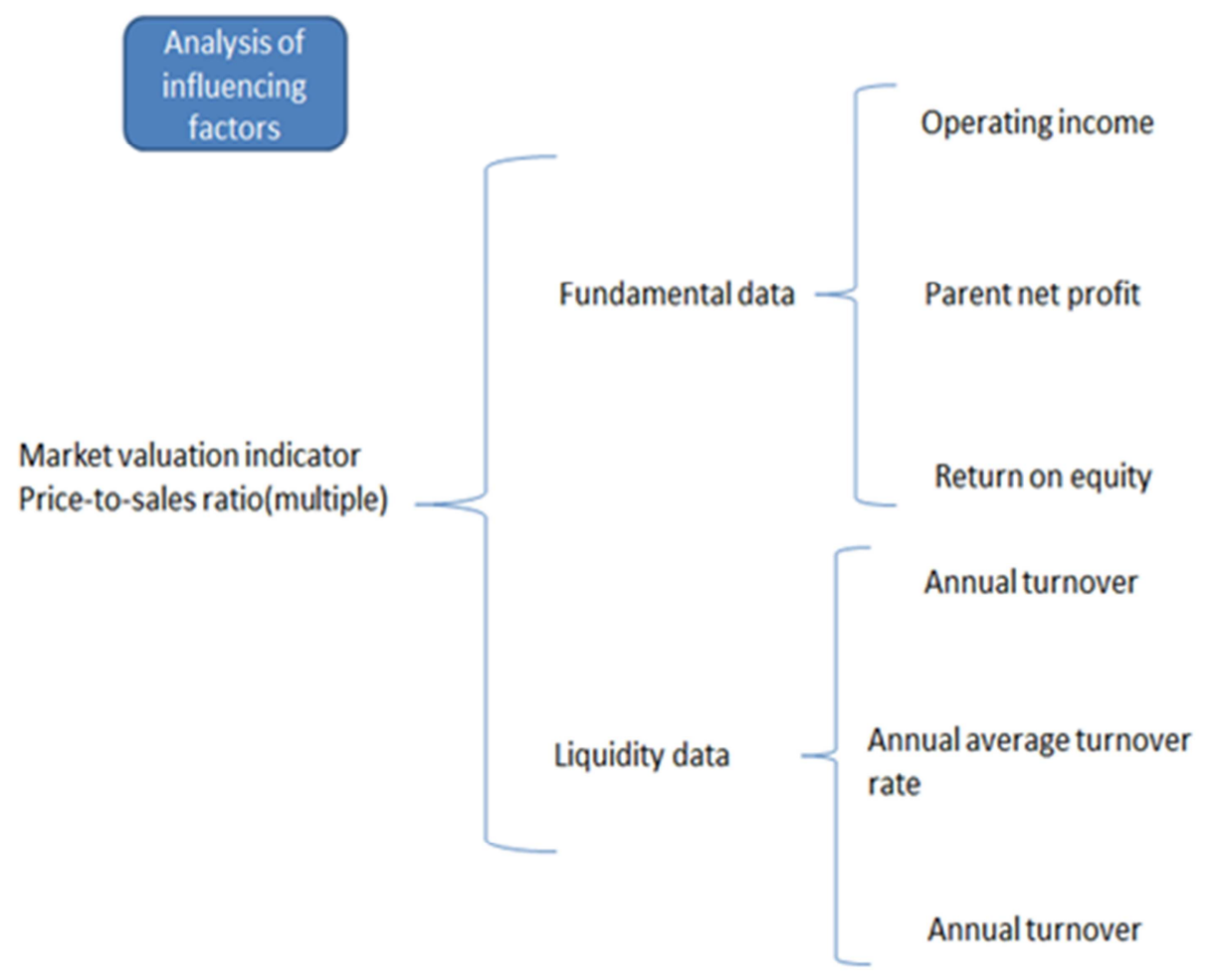

Figure 1. Analysis of influencing factor.

\subsection{Symbol Description}

Table 1. Main variable symbols in the text.

\begin{tabular}{ll}
\hline Symbol & Explanation \\
\hline$\beta$ & Price-to-sales ratio \\
$w$ & Operating income \\
$R$ & Parent net profit \\
$\alpha$ & Return on equity \\
$v$ & Annual turnover \\
$\eta$ & Annual turnover rate \\
$E$ & Annual turnover \\
$R$ & Comprehensive \\
\hline
\end{tabular}

First, confirm that you have the correct template for your paper size. This template has been tailored for output on the A4 paper size.

The symbols and meanings of the main symbol variables used in this paper are shown in table 1.

\subsection{Rough Processing of Model Data}

According to the data obtained by consulting, the relationship between industry and market sales rate can be analyzed.

Table 2. Industrial division

\begin{tabular}{ll}
\hline Define the symbol & Define the quantity \\
\hline$A$ & Agriculture, forestry, animal husbandry and fishery \\
$B$ & The mining industry \\
$C$ & manufacturing industry \\
$D$ & Production and supply of electricity, heat, gas, and water \\
$E$ & Construction industry \\
$F$ & Wholesale and retail \\
$G$ & Transportation, warehousing and postal service \\
$H$ & Information transmission, software, and information technology services \\
$I$ & Financial industry \\
$J$ & The real estate industry \\
$K$ & Leasing and business services \\
$L$ & Scientific research and technological services \\
$M$ & Water conservancy, environment and public facilities management \\
$N$ & Education \\
$O$ & Health and social work \\
$P$ & Culture, sports and entertainment \\
$Q$ & Accommodation and catering \\
$R$ & Comprehensive \\
\hline
\end{tabular}


We made a simple observation and analysis of the collected data. Companies with a low price-to-sales ratio have more room for growth than those with a high price-to-sales ratio. In both markets, the industries with the lowest average price-to-sales ratio are the manufacturing industry and the supply industry of heat, power, and water.

Among them, the steel industry has excess capacity, and most steel enterprises suffer severe losses, which makes investors choose to wait and see the situation of the whole industry. Most of the power, heat, and water supply industries are infrastructure construction, among which the traditional power and heat supply industries are impacted by the new energy industry, and investors choose to focus their investment in the new energy industry. The most enthusiastic investors in both markets are in sectors closely related to their lives, such as health, culture, and entertainment.

By comparing the two figures, it can be seen that for the industries in tier 1, tier 2 and tier 4 standards, the NASDAQ market of the United States and the a-share market of China were relatively stable from 2009 to 2018, and their average market/sales ratio did not fluctuate significantly. For the third-tier industry, the NASDAQ stock market in the United States fluctuated from 2011 to 2013, and investors' enthusiasm for this type of industry declined, but then returned to the average level. China's a-share market was more stable from 2009 to 2018. For the industry in level 5 standard, investors in the two markets have high enthusiasm for this kind of industry, most of which are strictly related to people's lives.

On the whole, the NASDAQ market of the United States is less volatile than the a-share market of China in this standard. Investors have been paying close attention to this kind of industry. China's a-share market is less stable, with investor enthusiasm peaking in 2012 but quickly cooling.

\subsection{Valuation Premium of Five Major Industries in China and the United States}

Establish a time series model. Set the observation sequence as $y_{1}, \Lambda, y_{T}$, and take the term number of moving average $N<T$. The calculation formula of a simple moving average is: Establish a time series model. Set the observation sequence as $y 1, \Lambda, y T$, and to take the term number of moving average $N<T$. The calculation formula of a simple moving average is:

$$
\mathrm{M}_{\mathrm{t}}=\left(\mathrm{y}_{\mathrm{t}}+\mathrm{y}_{\mathrm{t}-1}+\ldots+\mathrm{y}_{\mathrm{t}-\mathrm{N}+1}\right) / \mathrm{N}
$$

When the underlying trend of the prediction target fluctuates at a certain level, a simple moving average method can be used to establish the prediction model:

$$
\mathrm{Y}_{\mathrm{t}+1}=\mathrm{M}_{\mathrm{t}}=\left(\mathrm{y}_{\mathrm{t}}+\ldots+\mathrm{y}_{\mathrm{t}-\mathrm{N}+1}\right), \mathrm{t}=\mathrm{N}, \mathrm{N}+1, \ldots
$$

The standard error of prediction is:

$$
\mathrm{S}=\left(\sum\left(\mathrm{y}_{\mathrm{k}}-\mathrm{y}_{\mathrm{t}}\right) / \mathrm{T}-\mathrm{N}\right)^{0.5}
$$

Then it can be concluded that: premium (discount) rate $=$ (forecast market sales rate - actual market sales rate)/actual market sales rate (where, if the result is positive, it is a premium; Is negative, is the discount.

Price-to-sales ratio $=$ total market value/main business income.

Premium (discount) rate $=$ (forecast total market value actual total market value)/actual total market value

The indicators discussed here can be calculated conveniently in the daily individual stock return file of the CSMAR China stock market trading database. Specifically, first of all in the day under the frequency calculation of each trading day each stock $\mathrm{A} 0, \mathrm{~A}, \mathrm{~A}+, \mathrm{A}-, \mathrm{b}+, \mathrm{m}, \mathrm{A}, \mathrm{m}$, and then calculate each stock every month of the sum of the above indexes, and compute each stock trading days of each month, yields on trading days, with A positive yield of trading days, in the market rate of return of trading days and the market rate of return is negative number. Similarly, we also calculate the monthly sum of these indicators for each stock, the daily turnover rate, the daily stock trading amount and the daily stock (logarithmic) return rate. Finally, keep the last record of each stock every month to form data of about frequency.

Separate the standards, market rate as the vertical axis, time for the horizontal axis of a separate chart. The red polyline is the measured line obtained by data analysis. The broken blue line is the fitting line calculated according to the mathematical model. By observing and comparing the measured and fitted lines of each part, we can understand the premium or discount level of the NASDAQ market in the United States and China's

\begin{tabular}{|c|c|c|c|c|c|}
\hline \multicolumn{6}{|l|}{ China } \\
\hline reality & 0.480 & 1.5000 & 3.3600 & 6.830 & 14.140 \\
\hline simulation & 0.550 & 1.4567 & 3.2767 & 6.956 & 13.511 \\
\hline difference value & 0.070 & -0.043 & -0.083 & 0.126 & -0.6289 \\
\hline premium rate & 0.145 & -0.028 & -0.024 & 0.0185 & -0.0445 \\
\hline $\begin{array}{l}\text { America } \\
\text { reality }\end{array}$ & 0.5789 & 1.4883 & 3.0724 & 6.8941 & 13.4254 \\
\hline simulation & 0.6130 & 1.4928 & 3.2551 & 6.9260 & 13.8361 \\
\hline premium rate & 0.0588 & 0.0030 & 0.0595 & 0.0046 & 0.0306 \\
\hline
\end{tabular}
a-share market.

Table 3. Analysis of premium and discount.

A premium of $14.58 \%$; The measured end of the second-level standard line is higher than the fitting line, indicating that the expected market sales rate of investors in 2018 May be lower than the actual situation, with a discount 
of $2.89 \%$. However, the two-fold end of the three-level standard industry is separated, and the industry in this standard discounts $2.48 \%$ in the same year. The premium of $1.85 \%$ for four-level standard industries; The measured tail end of the five-level standard industry is higher than that of the fitted line, indicating that the industry in this standard will suffer a discount of $4.45 \%$ in 2018 .

Similarly, the NASDAQ market in the United States enjoys a $5.88 \%$ premium in tier 1 standard industry. $0.30 \%$ premium for second-tier industries; $5.95 \%$ premium for the industry in level 3 standard; $0.46 \%$ premium for industry in level 4 standard; The sector at level 5 is 3.06 percent premium.

\subsection{China and the United States A-share Market Comparison Model}

In order to analyze the relationship between the valuation index, underlying index, and liquidity index of China's a-share market and our market consult the literature "stock market liquidity index" [3] and get the relationship between stock liquidity and valuation index. Liquidity index was reviewed using the algorithm proposed by Amihud (2002):

$$
\text { ILLIQ }=1 / D_{\text {iy }}
$$

Among them, $\mid$ Riyd $\mid$ is the absolute value of the daily return of stock I on d day in y year, and VOLDiyd is the turnover. ILLIQiy is the stock price change level of each unit of trading volume, which measures the influence of order flow on price.

Brennan et al. (2013) further decomposed ILLIQiy ( $\mathrm{A}^{0}$ means ILLIQiy in the original text):

$$
\mathrm{A}^{0}=\mathrm{r} / \mathrm{DVOL}=\mathrm{A}(1 / \mathrm{S})
$$

Where $\mathrm{T}$ is daily turnover rate, $\mathrm{S}$ is market capsize, and $\mathrm{A}$ is ILLIQiy in the form of turnover rate.

$$
r^{+}=\max (0, r), r^{-}=\min (r, 0)
$$

Amuhud (2001) calculates each index once a year in the section analysis of stock return rate and adopts the following section regression equation:

$$
\mathrm{R}_{\mathrm{imy}}=\mathrm{k}_{\mathrm{omy}}+\mathrm{U}_{\mathrm{imy}}+\sum \mathrm{K}_{\mathrm{imy}} \mathrm{X}_{\mathrm{ji}, \mathrm{j}-1}
$$

$A^{0}$ Refers to the original Amihud index, which is the average value of $|r| / D V O L$ on the day of each month, $r$ refers to the daily return rate of stocks, and $D V O L$ refers to the daily turnover (thousand dollars).

$A^{0}$ is a measure of Amihud in the form of turnover rate, is the average of $|r| / T$ on each day, $T$ is the daily turnover rate, $A^{+}\left(A^{-}\right)$is a semi-amid measure on the rising (falling) day, and is the monthly average of daily $r^{+} / T\left(r^{-} / T\right) . A^{+}$, $m\left(A^{-}, m\right)$ are the semi-amihud measurement on the rising (falling) day of the stock market, and the monthly average of $|r| / T$ on the day when the weighted stock market return rate of CRSP market value is positive (negative).
All the indexes discussed here can be conveniently calculated in the daily stock return file of the CSMAR China stock market trading database. Specifically, first of all in the day under the frequency calculation of each trading day each stock $A^{0}, A^{+}, A^{-}, A_{m}^{+}, A_{m}^{-}$and then calculate each stock every month of the sum of the above indexes, and compute each stock trading days of each month, yields on trading days, with A positive yield of trading days, in the market rate of return of trading days and the market rate of return is negative number. Similarly, we calculate the daily turnover rate, daily trading amount of individual stocks, and daily (logarithm) rate of return. We also calculate the sum of these indicators per month for each stock. The last record of each stock every month is retained to form data about frequency.

In monthly frequency data, we can calculate the cumulative value of these indicators for $\mathrm{N}$ months, and then divide by the cumulative number of trading days for $\mathrm{N}$ months to get the average value of these indicators for $\mathrm{N}$ months.

We need to analyze the relationship between these indicators and future yields. If sorting method is adopted for analysis, the return rate of each stock in the future month $\mathrm{i}$ is set as follows: when the return rate in the future month is empty, the return rate in the future month $\mathrm{i}$ is set as empty; When the yield in the next 1 month is not empty, if the yield in the next $i$ month is empty, it is set to 0 .

From the data of monthly frequency, we analysis the indicators are: Amihud liquidity index $\left(A^{0}\right)$, turnover rate Amihud index, in the form of half Amihud index ( $A^{0}, A^{+}, A^{-}, A_{m}^{+}, A_{m}^{-}$), historical cumulative yield index $\mathrm{N}$ months, historical cumulative $\mathrm{N}$ months of average daily turnover rate, the logarithmic price, logarithmic circulation market value (one hundred million yuan), logarithmic value, history of total $\mathrm{N}$ months clinch A deal amount (RMB one hundred million).

\section{China and the United States A-share Market Comparison Model}

The relationship between market index, underlying index, and liquidity index is obtained by polynomial regression fitting equation. At the same time, the multiple factor weight analysis method is used to consider the proportion of annual operating income, annual parent net profit and annual return on equity in fundamental indicators, as well as the influence proportion of annual single stock trading volume, annual single stock trading amount and annual single stock average turnover rate in liquidity indicators. After analyzing the relationship between valuation index, underlying index, and liquidity index of Chinese and American markets, the differences between them are compared and analyzed.

The following chart can be obtained by organizing the data of the NASDAQ market in the United States and taking the market-to-sales ratio (value increased by ten times) as the horizontal axis:

It can be seen from the above figure that the listing and sales rate of the overall trend is negatively correlated with the 
operating income, and some industries or enterprises do not conform to the overall law. For example, Google (ALPHABET) -A, the price-to-sales ratio is about 9.02 times, but the revenue is $\$ 23,650,563,000$, which is far beyond the industry average. In general, the larger the market - sales ratio, the smaller the revenue.

In the overall trend of the marketing rate and return to mother net profit is positively correlated. Moreover, the peak value of net profit attributable to the parent company is reached at the market/sales ratio of 15 times, and the higher value of net profit attributable to the parent company is mostly distributed within the range of market/sales ratio of 10-20 times.

The relationship between the market price and return on equity is not very close and can be regarded as a direct ratio. That is, the higher the market sales ratio, the higher the return on equity, the more the stock is worth investing. However, the relationship between the two is not very clear, can not be a general rule.

To sum up, the price-to-sales ratio is negatively correlated with the underlying index; on the whole; that is, the larger the price-to-sales ratio is, the smaller the underlying index is. Fundamental indicators generally reflect the company's earnings, while the NASDAQ market in the United States does not require the earnings of the companies listed on the market, most of the enterprises through the traditional earnings indicators valuation is not reasonable.

Through the analysis of charts and data, it can be concluded that the market sales ratio is positively correlated with the annual turnover in general. However, as can be seen from the figure, there are several companies whose annual turnover far exceeds that of their peers. Moreover, most of them range from 6.5 to 14 times of market value.

On the whole, the marketing rate is proportional to the average turnover rate. That is, the higher the market turnover rate, the higher the turnover rate, the higher the stock liquidity. Generally speaking, the more people invest in a company, the higher the turnover rate of its stock, the more sufficient the company's cash flow, the better the company's operating condition.

\subsection{Analysis of Fundamental Indicators}

The price-to-sales ratio is inversely proportional to the fundamental indicators on the whole, which means that the smaller the price-to-sales ratio is, the higher the investment potential of the company and the higher its profitability. However, for roe, it's proportional. The higher the price-to-sales ratio, the higher the return on equity. There are many traditional enterprises in China's a-share market, which is suitable to use the $\mathrm{p} / \mathrm{e}$ valuation method. Therefore, the relationship between fundamental indicators and the price-to-sales ratio is not apparent, and there are contradictions in some aspects.

\subsection{Analysis of Liquidity Indicators}

For the liquidity indicator and the market rate, the two are inversely proportional to the whole. Among them, annual turnover has the most apparent relationship with the market sales rate. With the increase of the market sales rate, annual turnover becomes smaller and smaller. The relationship between the market turnover rate and the other two is not apparent in the figure, but it can be inferred roughly by observing the sample density and extreme value distribution: the annual turnover rate and annual turnover are inversely proportional to the market turnover rate. It can be concluded that in China's a stock market, the smaller the market/sales ratio, the stronger the liquidity of the stock; Correspondingly, with a small market/sales ratio, the company will have abundant cash flow, good loan repayment ability, and operating conditions, and the company will be worth investment.

Conclusion: on the NASDAQ market in the United States, the price-to-sales ratio is in direct proportion to the underlying index and the liquidity index. In China's a-share market, the price-to-sales ratio is inversely proportional to the underlying index and liquidity index.

\subsection{The Relationship Between Market-rate and Primary Face Index and Liquidity Index}

Assume that random variables subject to normal distribution can be expressed as follows:

$$
\mathrm{y}=\beta_{0}+\beta_{1} x_{1}+\ldots+\beta_{m} x_{m}+\mathcal{E}, \mathcal{E} \sim N\left(0, \sigma^{2}\right)
$$

The above model can also be obtained

$$
\begin{gathered}
\bar{y}=\beta_{0}+\beta_{1} x_{1}+\ldots+\beta_{m} x_{m}+\varepsilon=E(y) \\
\mathrm{yi}=\beta_{0}+\beta_{1} x_{1}+\ldots+\beta_{m} x_{m}+\varepsilon_{i}, \mathcal{E}_{i} \sim N\left(0, \sigma^{2}\right), i=1,2, \ldots, n
\end{gathered}
$$

The set of operational relations of the matrix can be expressed as:

$$
Y=N\left(X \beta, \sigma^{2} I_{n}\right)
$$

And then you plug it in $C / \beta=0.63 w+0.69 R+0.33 \alpha+0.64 v+0.64 \eta+0.63 E \quad(\mathrm{C}$ is a constant, and the formula reflects the inverse relationship between the market price ratio and the primary face index and liquidity index, which is consistent with the previous chart analysis).

\section{Conclusion}

Table 4. Share analysis of China and the United States.

\begin{tabular}{lll}
\hline Forecast in 2019 & China (RMB) & American (dollar) \\
\hline Operating income & $1.25 \times 10^{10}$ & $6.9 \times 10^{8}$ \\
Parent net profit & $9.69 \times 10^{8}$ & $2.9 \times 10^{7}$ \\
Return on equity & $5.41 \%$ & $0.6757 \%$ \\
Annual turnover & $3.13 \times 10^{9}$ & $2.3 \times 10^{7}$ \\
The annual average turnover rate & $447.2 \%$ & $71.76 \%$ \\
turnover & $3.7 \times 10^{9}$ & $5.9 \times 10^{10}$ \\
\hline
\end{tabular}

In order to predict the valuation level of the first batch of 
Chinese enterprises listed on the technology and innovation board, I quote the quantitative valuation model of the NASDAQ market in the United States:

$$
C / \beta=0.63 w+0.69 R+0.33 \alpha+0.64 v+0.64 \eta+0.63 E
$$

I am going to plug in the average to get a constant

$$
C=2.5^{*} 10^{\wedge} 8
$$

Table 5. Liquidity indicators for China's a-share market.

\begin{tabular}{ll}
\hline Indicators & Numerical value \\
\hline Annual turnover (shares) & 2139832136 \\
Annual average turnover rate (\%) & 442 \\
Annual turnover (us \$) & $22298964775 / 67300$ \\
\hline
\end{tabular}

Put into the formula to get:

The valuation level is about 1.3863 , which is in line with the actual level after the listing of the first batch of sci-tech innovation board enterprises in China.

\section{References}

[1] Zai-Ming H U. The Time Gap between Fiscal Investment and Regional Innovation Output--The Analysis of VAR Model Based on Time Series Data [J]. Economic Survey, 2017.

[2] Chu Z, Li B, Xiao H, et al. An Empirical Research on Indigenous Technological Innovation Process in Shenzhen City of China Based on Time Series Model [J]. Journal of Applied Sciences, 2013, 13 (8): 1245-1250.

[3] Geng Q F. Analysis of the Dynamic Correlation between China's Second Board and SME Board Based on Different Methods [J]. Applied Mechanics \& Materials, 2014, 687-691: 4938-4941.

[4] Yan-Yan H U. An Analysis of the Relationship between Cultural Trade and Economic Growth-Based on Time Series Model [J]. Economic Survey, 2015.

[5] Cao H, Tian L, Li S, et al. An integrated emergency response model for toxic gas release accidents based on cellular automata [J]. Annals of Operations Research, 2017, 255 (1-2): 617-638.
[6] Li M. Diversity of Board Interlocks and the Impact on Technological Exploration: A Longitudinal Study [J]. Journal of Product Innovation Management, 2019, 36 (4): 490-512.

[7] Lu W, Skjetne R, Løset S. A method for real-time estimation of full-scale global ice loads on floating structures [J]. Cold Regions Science and Technology, 2018: S0165232X17306018.

[8] Zhang Yanjun, Yang Xiaodong, Liu Yi, Zheng Dayuan, Bi Shujun. Research on the Frame of Intelligent Inspection Platform Based on Spatio-temporal Data. Computer \& Digital Engineering [J], 2019, 47 (03): 616-619+637.

[9] Bohl M A, Xu D S, Daniels L, et al. The Barrow Innovation Center case series: Early clinical experience with novel, low-cost techniques for bone graft containment in the posterolateral fusion bed. [J]. World Neurosurgery, 2018, 116: 285-295.

[10] Li H, Mollier A, Ziadi N, et al. The long-term effects of tillage practice and phosphorus fertilization on the distribution and morphology of corn root [J]. Plant and Soil, 2017, 412 (1-2): 97-114.

[11] Z. Zhao, J. Wang and Y. Liu, "User Electricity Behavior Analysis Based on K-Means Plus Clustering Algorithm," 2017 International Conference on Computer Technology, Electronics and Communication (ICCTEC), Dalian, China, 2017, pp. 484-487. doi: 10.1109/ICCTEC.2017.00111.

[12] Yi Liu, Jiawen Peng, and Zhihao Yu. 2018. Big Data Platform Architecture under The Background of Financial Technology: In The Insurance Industry As An Example. In Proceedings of the 2018 International Conference on Big Data Engineering and Technology (BDET 2018). ACM, New York, NY, USA, $31-35$

[13] Rolim C, Baptista P, Duarte G, et al. Real-Time Feedback Impacts on Eco-Driving Behavior and Influential Variables in Fuel Consumption in a Lisbon Urban Bus Operator [J]. IEEE Transactions on Intelligent Transportation Systems, 2017, PP (99): 1-11.

[14] Adepetu A, Keshav S. The relative importance of price and driving range on electric vehicle adoption: Los Angeles case study [J]. Transportation, 2017, 44 (2): 1-21. 